American Journal of Applied Sciences 7 (1): 102-109, 2010

ISSN 1546-9239

(C) 2010 Science Publications

\title{
Piecewise Sliding Mode Decoupling Fault Tolerant Control System
}

\author{
Rafi Youssef and Hui Peng \\ Department of Automatic Control Engineering, \\ School of Information Science and Engineering, \\ Central South University, Changsha, 410083
}

\begin{abstract}
Problem statement: Proposed method in the present study could deal with fault tolerant control system by using the so called decentralized control theory with decoupling fashion sliding mode control, dealing with subsystems instead of whole system and to the knowledge of the author there is no known computational algorithm for decentralized case, Approach: In this study we present a decoupling strategy based on the selection of sliding surface, which should be in piecewise sliding surface partition to apply the PwLTool which have as purpose in our case to delimit regions where sliding mode occur, after that as Results: We get a simple linearized model selected in those regions which could depict the complex system, Conclusion: With the 3 water tank level system as example we implement this new design scenario and since we are interested in networked control system we believe that this kind of controller implementation will not be affected by network delays.
\end{abstract}

Key words: Sliding-mode control, fault tolerant, decoupling system fashion, order reduction, piecewise sliding mode

\section{INTRODUCTION}

The Fault tolerant control methodologies can be divided into two categories, one is a passive fault tolerant control system and the other is an active fault tolerant control system (Rauch, 1994; Huzmezan and Maciejowski, 1998a). Nonlinear control scheme is one of the most widely used active fault tolerant control methods, because several nonlinear control methods such as sliding mode controller, feedback linearization, could handle it.

Reconfigurable control is a critical technology (Huzmezan and Maciejowski, 1998b; Rauch, 1995) with its objectives to detect the fault and recover the functionality of the faulty system as same as that of the nominal system (Yang and Blanke, 2000). Various methods are used for reconfigurable control to cover the requirements of different applications. The behavior of the reconfigurable control depends upon whether the approach is passive or active.

Such control ideas have been implemented on a variety of military and commercial applications in last two decades to accommodate fault.

The idea to use sliding mode control for reconfiguration purposes come from the fact that this method alleviates the problems caused by uncertain or changing system dynamics or parameters. This is the case when a fault occurs in a system component.
The main reason for this popularity is its attractive property such as applicability to multi input multi output systems.

Sliding mode control is based on variable structure systems theory: The control commutates in order to force the systems motions to act in particular manner on a desired surface (called the sliding surface). Sliding regimes are unaffected by perturbations satisfying the well-known matching conditions (Drazenovic, 1969; El-Ghezaoui et al., 1983).

The choice of the surface is mostly related to some stabilization problem: The shape of the surface is selected a priori, leading to a set of parameters that are to be computed (adjusted) in order to obtain the desired dynamics (El-Ghezaoui et al., 1983; Esfandiari and Khalil, 1991).

Problem statement: Typical description for the system uncertainty caused by system faults (Khan and Spurgeon, 2006) can be represented with:

$$
\begin{aligned}
& \dot{x}(t)=A x(t)+B u(t)+R f(t) \\
& y(t)=C x(t)
\end{aligned}
$$

Where:

$\mathrm{x}(\mathrm{t}) \in \mathfrak{R}^{\mathrm{n}}=$ The state vector

$\mathrm{u}(\mathrm{t}) \in \mathfrak{R}^{1}=$ The control input vector

Corresponding Author: Rafi Youssef, Department of Automatic Control Engineering,

School of Information Science and Engineering, Central South University, Changsha, 410083 
Am. J. Applied Sci., 7 (1): 102-109, 2010

$\mathrm{y}(\mathrm{t}) \in \mathfrak{R}^{\mathrm{m}}=$ The measurement vector

$\mathrm{f}(\mathrm{t}) \in \mathfrak{R}^{\mathrm{g}}=$ Represents the fault vector which is considered as an unknown function of time

Assume $\{\mathrm{C}, \mathrm{A}\}$ is observable, $\mathrm{R}$ matrix is the distribution matrix and $\mathrm{Rf}(\mathrm{t})$ the uncertainty caused by system or actuator fault that could be inserted into A and $\mathrm{B}$, then:

$$
\mathrm{A}_{\text {fault }}=\mathrm{A}+\Delta \mathrm{A} \text { and } \mathrm{B}_{\text {fault }}=\mathrm{B}+\Delta \mathrm{B}
$$

With $\mathrm{Rf}(\mathrm{t})=\Delta \mathrm{Ax}(\mathrm{t})$ system fault or $\mathrm{Rf}(\mathrm{t})=\Delta \mathrm{Bx}(\mathrm{t})$ actuator fault.

System description in decoupled fashion sliding mode: Consider a second-order nonlinear system, which can be represented by the following state-space model in a canonical form:

$$
\left\{\begin{array}{l}
\dot{\mathrm{x}}_{1}(\mathrm{t})=\mathrm{x}_{2}(\mathrm{t}) \\
\dot{\mathrm{x}}_{2}(\mathrm{t})=\mathrm{f}(\mathrm{x})+\mathrm{b}(\mathrm{x}) \mathrm{u}+\mathrm{d}(\mathrm{t}) \\
\mathrm{y}(\mathrm{t})=\mathrm{x}_{1}(\mathrm{t})
\end{array}\right.
$$

Where:

$$
\begin{array}{ll}
\mathrm{x}=\left[\mathrm{x}_{1} \mathrm{x}_{2}\right]^{\mathrm{T}}= & \text { The state vector, } \mathrm{f}(\mathrm{x}) \text { and } \mathrm{b}(\mathrm{x}) \text { are } \\
& \text { nonlinear functions } \\
\mathrm{u} & \text { The control input } \\
\mathrm{u}(\mathrm{t}) \quad & \text { The external disturbance }
\end{array}
$$

The disturbance is assumed to be bounded as $|d(t)| \leq D(t)$. For this kind of the second order system; we can use many kinds of control methods, such as, fuzzy control, PID control, sliding-mode control. A control law u can be easily designed to make the second order system (2) arrive at our control goal. However, for nonlinear MIMO models, the system dynamic representation is generally not in a canonical form exactly. Rather, it has a form shown below:

$$
\left\{\begin{array}{l}
\dot{\mathrm{x}}_{1}(\mathrm{t})=\mathrm{x}_{2}(\mathrm{t}) \\
\dot{\mathrm{x}}_{2}(\mathrm{t})=\mathrm{f}_{1}(\mathrm{x})+\mathrm{b}_{1}(\mathrm{x}) \mathrm{u}_{1}+\mathrm{d}_{1}(\mathrm{t}) \\
\dot{\mathrm{x}}_{3}(\mathrm{t})=\mathrm{x}_{4}(\mathrm{t}) \\
\dot{\mathrm{x}}_{4}(\mathrm{t})=\mathrm{f}_{2}(\mathrm{x})+\mathrm{b}_{2}(\mathrm{x}) \mathrm{u}_{2}+\mathrm{d}_{2}(\mathrm{t})
\end{array}\right.
$$

Where:

$$
\begin{array}{ll}
\mathrm{x}=\left[\mathrm{x}_{1} \mathrm{x}_{2} \mathrm{x}_{3} \mathrm{x}_{4}\right]^{\mathrm{T}} & =\text { The state vector } \\
\mathrm{f}_{1}(\mathrm{x}), \mathrm{f}_{2}(\mathrm{x}) \text { and } & =\text { Nonlinear functions } \\
\mathrm{b}_{1}(\mathrm{x}), \mathrm{b}_{2}(\mathrm{x}) & =\text { The control inputs } \\
\mathrm{u}_{1}, \mathrm{u}_{2} & =\text { External disturbances } \\
\mathrm{d}_{1}(\mathrm{t}), \mathrm{d}_{2}(\mathrm{t}) &
\end{array}
$$

The disturbances are assumed to be bounded as $\left|\mathrm{d}_{1}(\mathrm{t})\right| \leq \mathrm{D}_{1}(\mathrm{t}),\left|\mathrm{d}_{2}(\mathrm{t})\right| \leq \mathrm{D}_{2}(\mathrm{t})$. From (3), one can design $\mathrm{u}_{1}$ and $\mathrm{u}_{2}$ respectively, as subsystem in (3). However in complex systems, where it may be presented as (3) but hard to make a subsystem control on it, could go through the idea of decoupled method to design a control $u$ to govern the whole system.

Design decoupled sliding mode: Suppose it were possible to design a control that constrains the motion of the system to the manifold:

$\mathrm{s}_{1}=\left\{\mathrm{x} / \mathrm{c}_{1}\left(\mathrm{x}_{1}-\mathrm{z}\right)+\mathrm{x}_{2}=\left[\mathrm{c}_{1} 1\right]\left[\mathrm{x}_{1} \mathrm{x}_{2}\right]^{\mathrm{T}}-\mathrm{c}_{1} \mathrm{z}\right\}$

Where:

$\mathrm{s}_{1}=$ The sliding surface

$c_{1}=$ Defining the slope of the sliding surface $s_{1}$ and the other switching surface presented as follow:

$\mathrm{S}_{2}=\left\{\mathrm{x} / \mathrm{c}_{2} \mathrm{x}_{3}+\mathrm{x}_{4}\right\}$

with $\mathrm{c}_{2}$ is slop term of sliding surface $\mathrm{s}_{2}$.

The best approximation $\hat{u}$ of a continuous control law that would achieve $\dot{\mathrm{s}}_{1}=0$ is thus:

$\hat{\mathrm{u}}_{1}=\mathrm{b}^{-1}\left(-\mathrm{c}_{1} \mathrm{x}_{2}+\mathrm{c}_{1} \dot{\mathrm{z}}-\mathrm{f}_{1}-\mathrm{d}_{1}\right)$

Where:

$\dot{\mathrm{s}}_{1}=\mathrm{c}_{1}\left(\dot{\mathrm{x}}_{1}-\dot{\mathrm{z}}\right)+\dot{\mathrm{x}}_{2}=\mathrm{c}_{1} \mathrm{x}_{2}-\mathrm{c}_{1} \dot{\mathrm{z}}+\mathrm{f}_{1}+\mathrm{b}_{1} \mathrm{u}_{1}+\mathrm{d}_{1}=0$

The decoupled sliding-mode control input is to be chosen as follows for a Lyapunov function candidate:

$\mathrm{V}=\frac{1}{2} \mathrm{~S}_{1}^{2}$

and its derivative gives:

$\dot{\mathrm{V}}=\mathrm{s}_{1} \dot{\mathrm{s}}_{1}=\mathrm{s}_{1}\left(\mathrm{c}_{1} \mathrm{x}_{2}-\mathrm{c}_{1} \dot{\mathrm{z}}+\mathrm{f}_{1}+\mathrm{b}_{1} \mathrm{u}_{1}+\mathrm{d}_{1}\right)$

such that outside of $\mathrm{s}_{1}(\mathrm{t})$, the following condition should hold:

$\dot{\mathrm{V}}=\mathrm{s}_{1} \dot{\mathrm{s}}_{1} \leq-\eta\left|\mathrm{s}_{1}\right|$

In order to satisfy sliding condition (10) despite uncertainty of the dynamics, we add û to a term discontinuous across the surface $s_{1}=0$ in way that we get: 
Am. J. Applied Sci., 7 (1): 102-109, 2010

$\mathrm{u}=\hat{\mathrm{u}}-\mathrm{M}^{*} \operatorname{sign}\left(\mathrm{s}_{1}\right)$

By choosing $\mathrm{M}$ in (11) to be large enough, or take $D_{1}(t) /\left|d_{1}(t)\right| \leq M$ as in (Slotine and Li, 1991) we can now guarantee that (10) verified.

Remark 1: In the same sequence as in (6), (7) and (11) respectively we could get the control law base on the second sliding surface $s_{2}$, however, in manner to well pose the decentralized method we select to deal with one sliding surface $s_{1}$, since the system is divided into two subsystem and we could control the first one and take the other subsystem as feeding information for the first one, both operation surface may be connected via the variable $z$, since $s_{1}$ and $s_{2}$ are analogical and one could be augmented by the term $\left(-c_{1} z\right)$ as in (4), where $\mathrm{z}$ could be bounded value.

Remark 2: $c_{1}$ and $c_{2}$ has strong influence on the behavior in the transient state of the system. Appropriate choice of sliding factor is necessary for achieving favorable transient response.

The control input is the sliding-mode control of subsystem chosen, Since in sliding-mode control theory it is assumed that $\mathrm{u}=\mathrm{u}_{1}$ to control the entire system, the boundary of $\mathrm{x}_{1}$ can be assured with $0 \prec \mathrm{z}_{\mathrm{u}} \prec 1$ and $|z| \leq z_{u}$, means that absolute value of $x_{1}$ is always bounded. Here, $z_{u}$ is the upper limit of $z$.

Therefore, $\mathrm{z}$ is a decaying signal, since $\mathrm{z}_{\mathrm{u}}$ is less than one. The control action is accomplished as follows: The main object of (4) is to make $x_{1}$ and $x_{2}$ equal to zero according to the sliding-mode control theory. But when $s_{2} \neq 0$ then $z \neq 0$ in (4). This causes (6) to apply an input such that $\mathrm{z}$ is decreased. When $\mathrm{z}$ is decreased, $\mathrm{s}_{2}$ will be decreased too.

\section{Piecewise sliding mode:}

Piecewise sliding surface: Taking the sliding surface presented in the (4) could be written as follow:

$$
\left\{\begin{array}{c}
S=\left(\begin{array}{lll}
C_{1} & 1 & -C_{1} Z
\end{array}\right)\left(\begin{array}{l}
x_{1} \\
x_{2} \\
1
\end{array}\right) \\
=G\left(\begin{array}{lll}
x_{1} & x_{2} & 1
\end{array}\right)^{T}
\end{array}\right.
$$

Such:

$$
\mathrm{G}=\left[\begin{array}{lll}
\mathrm{C}_{1} & 1 & -\mathrm{C}_{1} \mathrm{Z}
\end{array}\right]
$$

where, $\mathrm{C}_{1}$ and $\mathrm{Z}$ are parameters of sliding surface $\mathrm{S}$ that could be written in subscript fashion such:
$\mathrm{S}_{\mathrm{i}}=\mathrm{G}_{\mathrm{i}}\left(\mathrm{x}_{1} \mathrm{x}_{2} 1\right)^{\mathrm{T}}$

Where:

$\mathrm{G}_{\mathrm{i}}=\left(\mathrm{C}_{\mathrm{i}} 1-\mathrm{C}_{\mathrm{i}} \mathrm{Z}\right) \quad \mathrm{i} \in \mathbb{N}$

And as seen in remark2 where $0 \prec \mathrm{z}_{\mathrm{u}} \prec 1$.

We take:

$|\mathrm{z}| \leq \mathrm{z}_{\mathrm{u}}$

The inequality (16) shows that the sliding mode is not unique and $G_{i}$ will take different value even by fixing $\mathrm{C}_{\mathrm{i}}$.

Still need to specify regions where the sliding occur following the partition that we may choose.

Controller design: The concern now is that the state $\left(\mathrm{x}_{1}, \dot{\mathrm{x}}_{1}\right)$ can slide along the piecewise sliding mode.

In way to use PWL tools elaborated in (Johansson and Rantzer, 1998), Eq. 15 and 16 used as piecewise sliding surface partition.

Then seek matched operation points with partitions, where sliding mode happen, then we will select some of those point to linearize the system in way to get good approximation model of the system and after that, design the controller with techniques explained in this paragraph, the flowchart in Fig. 1.

Let be a non linear system with second order transfer function of the form:

$\frac{\mathrm{H}_{2}}{\mathrm{Q}_{1}}=\frac{\mathrm{k}}{\left(\tau_{1} \mathrm{~s}+1\right)\left(\tau_{2} \mathrm{~s}+1\right)}$

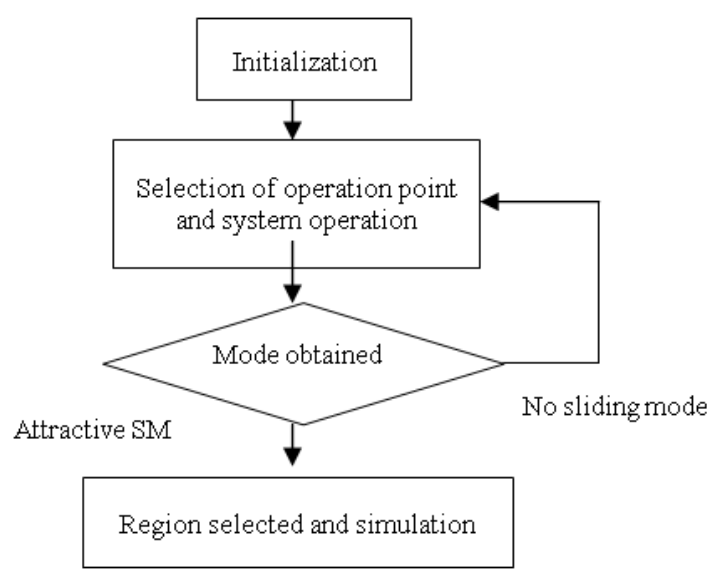

Fig. 1: Algorithm followed to select regions where to linearize the system 
In order to find the gain, $\mathrm{G}$ and the time constants, $\tau_{1}$ and $\tau_{2}$, of this second order system, an open loop step response experiment is carried out using the Simulink, (17) could be in the form of:

$\mathrm{G}(\mathrm{s})=\frac{\mathrm{H}_{2}}{\mathrm{Q}_{1}}=\frac{\mathrm{k} \times \omega^{2}}{\mathrm{~s}^{2}+2 \xi \omega \mathrm{s}+\omega^{2}}$

Where:

$$
\omega^{2}=\frac{1}{\left(\tau_{1} \times \tau_{2}\right)}
$$

and

$$
2 \xi=\left(\frac{1}{\tau_{1}}+\frac{1}{\tau_{2}}\right)
$$

Then with (13) cross multiply:

$$
\mathrm{s}^{2} \mathrm{H}_{2}+2 \xi \omega \mathrm{H}_{2} \mathrm{~s}+\omega^{2} \mathrm{H}_{2}=\mathrm{k} \times \omega^{2} \mathrm{Q}_{1}
$$

Finally:

$\ddot{\mathrm{H}}_{2}+2 \xi \omega \dot{\mathrm{H}}_{2}+\omega^{2} \mathrm{H}_{2}=\mathrm{k} \times \omega^{2} \mathrm{Q}_{1}$

We define now $x_{1}$ and $x_{2}$ to be equal to the two state variables:

$$
\left\{\begin{array}{l}
\mathrm{x}_{1}=\mathrm{H}_{2} \rightarrow \dot{\mathrm{x}}_{1}=\dot{\mathrm{H}}_{2} \\
\mathrm{Q}_{1}=\mathrm{u} \\
\mathrm{x}_{2}=\dot{\mathrm{x}}_{1}=\dot{\mathrm{H}}_{2} \rightarrow \dot{\mathrm{x}}_{2}=\ddot{\mathrm{H}}_{2}
\end{array}\right.
$$

We write the equation out with the new defined states and by substituting (20) into (19):

We get:

$\left\{\begin{array}{l}\dot{\mathrm{x}}_{1}=\mathrm{x}_{2} \\ \dot{\mathrm{x}}_{2}=-2 \xi \omega \mathrm{x}_{2}-\omega^{2} \mathrm{x}_{1}+\mathrm{k} \times \omega^{2} \mathrm{u}\end{array}\right.$

We can now write this in state space form:

$$
\left\{\begin{array}{l}
{\left[\begin{array}{l}
\dot{x}_{1} \\
\dot{x}_{2}
\end{array}\right]=\left(\begin{array}{cc}
0 & 1 \\
-\omega^{2} & -2 \xi \omega
\end{array}\right)\left[\begin{array}{l}
x_{1} \\
x_{2}
\end{array}\right]+\left[\begin{array}{l}
0 \\
k \times \omega^{2}
\end{array}\right] \mathrm{u}} \\
y=[10]\left[\begin{array}{l}
x_{1} \\
x_{2}
\end{array}\right]
\end{array}\right.
$$

Looks like:

$$
\left\{\begin{array}{l}
\dot{X}=A X+B U \\
y=C X+D U
\end{array}\right.
$$

where, $\mathrm{D}$ is zeros matrix: and

$$
\begin{gathered}
A=\left(\begin{array}{cc}
0 & 1 \\
-\omega^{2} & -2 \xi \omega
\end{array}\right) \\
B=\left[\begin{array}{l}
0 \\
k \times \omega^{2}
\end{array}\right] \\
C=\left[\begin{array}{l}
1 \\
0
\end{array}\right]
\end{gathered}
$$

If we consider the close loop with step input, then error is defined as:

$$
\mathrm{e}(\mathrm{s})=\frac{\mathrm{r}(\mathrm{s})}{1+\mathrm{G}(\mathrm{s})}
$$

Then (18) becomes:

$\frac{e(s)}{r(s)}=\frac{1}{1+G(s)}$

Substituting (23) into (25) lead to:

$\frac{\mathrm{e}(\mathrm{s})}{\mathrm{r}(\mathrm{s})}=\frac{\mathrm{s}^{2}+2 \xi \omega \mathrm{s}+\omega^{2}}{\mathrm{~s}^{2}+2 \xi \omega \mathrm{s}+\omega^{2}+\mathrm{k} \times \omega^{2}}$

Cross multiplication of (26) gives us:

$\mathrm{e}(\mathrm{s})\left(\mathrm{s}^{2}+2 \xi \omega \mathrm{s}+\omega^{2}+\mathrm{k} \times \omega^{2}\right)=\mathrm{r}(\mathrm{s})\left(\mathrm{s}^{2}+2 \xi \omega \mathrm{s}+\omega^{2}\right)$

Since $r(s)$ is a step input and its derivative is zero then (27) becomes:

$\ddot{\mathrm{e}}+2 \xi \omega \dot{\mathrm{e}}+2 \omega^{2} \mathrm{ke}=\omega^{2} \mathrm{r}$

Then if we take:

$$
\left\{\begin{array}{l}
\mathrm{x}_{1}=\mathrm{e} \\
\text { and } \\
\dot{\mathrm{x}}_{1}=\dot{\mathrm{e}}=\mathrm{x}_{2} \\
\mathrm{r}=\mathrm{u}
\end{array}\right.
$$

then we reach the state space:

$\left\{\begin{array}{l}\dot{x}_{1}=x_{2} \\ \dot{x}_{2}=-2 \xi \omega x_{2}-2 \omega^{2} k_{1}+\omega^{2} u\end{array}\right.$ 


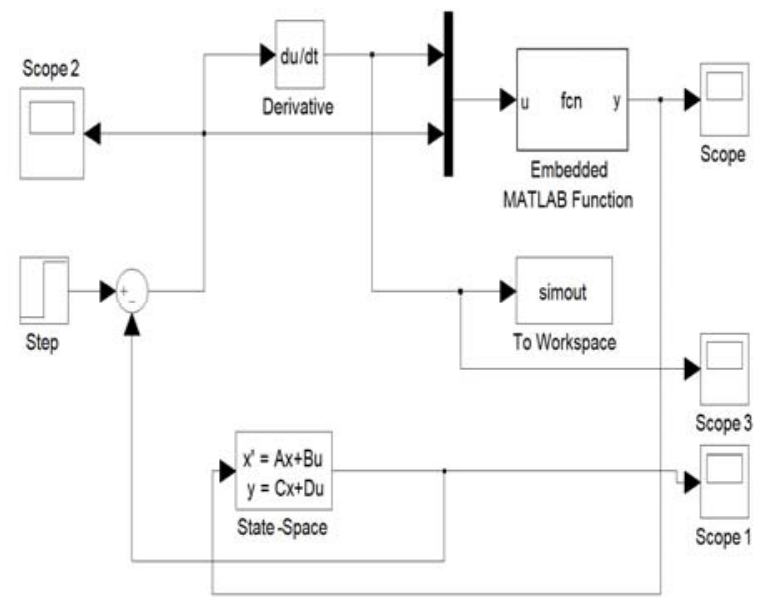

Fig. 2: Simulink model

Finally we obtain the form:

$$
\left\{\begin{array}{l}
{\left[\begin{array}{l}
\dot{x}_{1} \\
\dot{x}_{2}
\end{array}\right]=\left(\begin{array}{cc}
0 & 1 \\
-2 \omega^{2} \mathrm{k} & -2 \xi \omega
\end{array}\right)\left[\begin{array}{l}
\mathrm{x}_{1} \\
\mathrm{x}_{2}
\end{array}\right]+\left[\begin{array}{l}
0 \\
\omega^{2}
\end{array}\right] \mathrm{u}} \\
\mathrm{y}=[10]\left[\begin{array}{l}
\mathrm{x}_{1} \\
\mathrm{x}_{2}
\end{array}\right]
\end{array}\right.
$$

Then model of sliding mode controller regarding to the state space above (Fig. 2).

\section{MATERIALS AND METHODS}

To Design the decoupled sliding mode controller we use the example of three water tank system Fig. 3, existent in our lab, the Simulink/Matlab and PwLTool package are adopted for this implementation

Things done with PwLTool: This package serve in our case to find a global quadratic lyapunov function to verify stability of the piecewise linear system, i.e., to find non empty $\mathrm{P}$, the computations are performed using convex optimization in terms of Linear Matrix Inequality (LMI)

\section{RESULTS}

For this system, the design objective is to maintain the liquid level of the tank 2 (B) at a desired height and to keep the changes of the liquid level within a certain limit in the presence of large disturbances or process faults, Thus, the system has one output, i.e., the liquid level in tank 2 (Fig. 3).

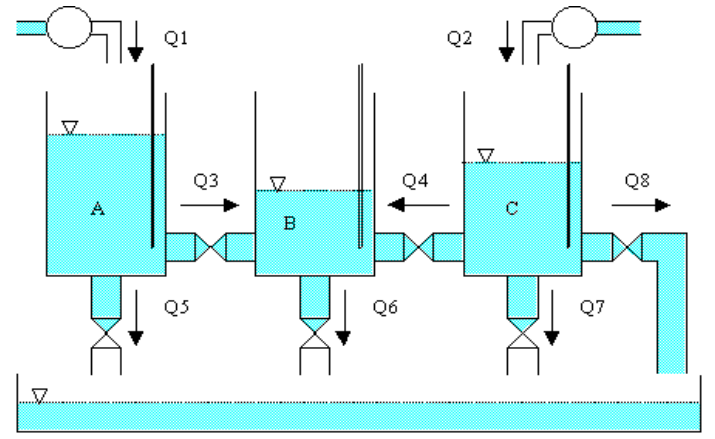

Fig. 3: Three water tank level system

In this example, we will specifically focus on the FTCS against process faults. The fault considered is the leakage of tank 2 occurring in the draining valve, $\mathrm{V}_{2}$ which can be modeled by an abrupt change in the flow resistance $R_{2}$.

Mathematical model: From the law of mass conservation, we can write out the dynamic relationships between the height of the Liquid levels and the inlet and outlet flow rates as follows:

$\left\{\begin{array}{l}\mathrm{s}_{1} \frac{\mathrm{dH}_{1}}{\mathrm{dt}}=\left(\mathrm{Q}_{1}-\mathrm{Q}_{3}-\mathrm{Q}_{5}\right) \\ \mathrm{s}_{2} \frac{\mathrm{dH}}{\mathrm{dt}}=\left(\mathrm{Q}_{4}+\mathrm{Q}_{3}-\mathrm{Q}_{6}\right) \\ \mathrm{s}_{3} \frac{\mathrm{dH}}{\mathrm{dt}}=\left(\mathrm{Q}_{2}-\mathrm{Q}_{8}-\mathrm{Q}_{7}-\mathrm{Q}_{4}\right)\end{array}\right.$

with the valve with flow rate $\mathrm{Q}_{8}$ is closed then $\mathrm{Q}_{8}$ equal to zeros,

Where:

$$
\begin{aligned}
& \mathrm{Q}_{5}=\mathrm{K}_{5} \sqrt{\mathrm{gH}_{1}} \\
& \mathrm{Q}_{6}=\mathrm{K}_{6} \sqrt{\mathrm{gH}_{2}} \\
& \mathrm{Q}_{7}=\mathrm{K}_{7} \sqrt{\mathrm{gH}_{3}}
\end{aligned}
$$

and

$$
\left\{\begin{array}{l}
\mathrm{Q}_{4}=\mathrm{K}_{4} \operatorname{sign}\left(\mathrm{H}_{3}-\mathrm{H}_{2}\right) \sqrt{\mathrm{g}\left|\mathrm{H}_{3}-\mathrm{H}_{2}\right|} \\
\mathrm{Q}_{3}=\mathrm{K}_{3} \operatorname{sign}\left(\mathrm{H}_{1}-\mathrm{H}_{2}\right) \sqrt{\mathrm{g}\left|\mathrm{H}_{1}-\mathrm{H}_{2}\right|}
\end{array}\right.
$$

and the parameters are defined as: $K_{j}=\frac{\rho}{R_{j}}$ with $j=1,2,3,4,5,6,7,8$. 
Where $\mathrm{g}$ is the acceleration of gravity, substituting (31-32) one can obtain the following equation to describe the coupled tank system:

$$
\left\{\begin{aligned}
\frac{\mathrm{dH}_{1}}{\mathrm{dt}=} & \frac{1}{\mathrm{~s}_{1}}\left(\mathrm{Q}_{1}-\mathrm{K}_{3} \operatorname{sign}\left(\mathrm{H}_{1}-\mathrm{H}_{2}\right) \sqrt{\mathrm{g}\left|\mathrm{H}_{1}-\mathrm{H}_{2}\right|}\right. \\
& \left.-\mathrm{K}_{5} \sqrt{\mathrm{gH}_{1}}\right) \\
\frac{\mathrm{dH}_{2}}{\mathrm{dt}}= & \frac{1}{\mathrm{~s}_{2}}\left(\mathrm{~K}_{4} \operatorname{sign}\left(\mathrm{H}_{2}-\mathrm{H}_{3}\right) \sqrt{\mathrm{g}\left|\mathrm{H}_{2}-\mathrm{H}_{3}\right|}\right. \\
& \left.+\mathrm{K}_{3} \operatorname{sign}\left(\mathrm{H}_{1}-\mathrm{H}_{2}\right) \sqrt{\mathrm{g}\left|\mathrm{H}_{1}-\mathrm{H}_{2}\right|}-\mathrm{K}_{6} \sqrt{\mathrm{gH}_{2}}\right) \\
\frac{\mathrm{dH}_{3}}{\mathrm{dt}}= & \frac{1}{\mathrm{~s}_{3}}\left(\mathrm{Q}_{2}-\mathrm{K}_{7} \sqrt{\mathrm{gH}_{3}}\right. \\
& \left.-\mathrm{K}_{4} \operatorname{sign}\left(\mathrm{H}_{2}-\mathrm{H}_{3}\right) \sqrt{\mathrm{g}\left|\mathrm{H}_{2}-\mathrm{H}_{3}\right|}\right)
\end{aligned}\right.
$$

Model linearization: Clearly, the system is non-linear. When linearized around an operating point $\left(\mathrm{H}_{01}, \mathrm{H}_{02}\right.$, $\mathrm{H}_{03}$ ) (it is assumed that $\mathrm{H}_{01}>\mathrm{H}_{02}>\mathrm{H}_{03}$ ), the following linear model can be obtained:

Where:

$$
\begin{aligned}
& {\left[\begin{array}{c}
\Delta \dot{\mathrm{H}}_{1} \\
\Delta \dot{\mathrm{H}}_{2} \\
\Delta \dot{\mathrm{H}}_{3}
\end{array}\right]} \\
& =\left(\begin{array}{ccc}
-\mathrm{k}_{3} \alpha_{12}-\mathrm{k}_{5} \alpha_{1} & \mathrm{k}_{3} \alpha_{12} & 0 \\
\mathrm{k}_{3} \alpha_{21} & \mathrm{k}_{4} \alpha_{23}-\mathrm{k}_{3} \alpha_{21}-\mathrm{k}_{6} \alpha_{2} & -\mathrm{k}_{4} \alpha_{23} \\
0 & -\mathrm{k}_{4} \alpha_{32} & -\mathrm{k}_{7} \alpha_{3}+\mathrm{k}_{4} \alpha_{32}
\end{array}\right) \\
& {\left[\begin{array}{c}
\Delta \mathrm{H}_{1} \\
\Delta \mathrm{H}_{2} \\
\Delta \mathrm{H}_{3}
\end{array}\right]+\left(\begin{array}{cc}
\frac{1}{\mathrm{~s}_{1}} & 0 \\
0 & 0 \\
0 & \frac{1}{\mathrm{~s}_{3}}
\end{array}\right)\left[\begin{array}{l}
\mathrm{Q}_{1} \\
\mathrm{Q}_{2}
\end{array}\right]}
\end{aligned}
$$

Where:

$$
\begin{aligned}
& \alpha_{12}=\frac{1}{2 \mathrm{~S}_{1} \sqrt{\left|\mathrm{H}_{01}-\mathrm{H}_{02}\right| / g}} \\
& \alpha_{21}=\frac{1}{2 \mathrm{~S}_{2} \sqrt{\left|\mathrm{H}_{01}-\mathrm{H}_{02}\right|} / \mathrm{g}} \\
& \alpha_{23}=\frac{1}{2 \mathrm{~S}_{2} \sqrt{\left|\mathrm{H}_{02}-\mathrm{H}_{03}\right| / g}} \\
& \alpha_{32}=\frac{1}{2 \mathrm{~S}_{3} \sqrt{\left|\mathrm{H}_{02}-\mathrm{H}_{03}\right|} / \mathrm{g}} \\
& \alpha_{1}=\frac{1}{2 \mathrm{~S}_{1} \sqrt{\mathrm{H}_{01}}}
\end{aligned}
$$

$$
\begin{aligned}
& \alpha_{2}=\frac{1}{2 \mathrm{~S}_{2} \sqrt{\mathrm{H}_{02}}} \\
& \alpha_{3}=\frac{1}{2 \mathrm{~S}_{3} \sqrt{\mathrm{H}_{03}}}
\end{aligned}
$$

Detection sliding mode: The choice of $G_{i}$ is piecewise heuristic under the condition given in (16).

And the LMI feasibility problem computation to get:

$$
\mathrm{P}=\left(\begin{array}{ccc}
2.8303 & 0.0042 & -1.1488 \\
0.0042 & 3.8902 & -0.3467 \\
-1.1488 & -0.3467 & 3.2735
\end{array}\right)
$$

where, $\mathrm{P}$ is the quadratique lyapunov function.

So far we have obtained the mathematical model of the whole tank system depicted previously in the region where sliding mode occur following the algorithm described in (piecewise sliding mode paragraph)

In fact, in this design example, the drainage of tank 1-3 are assumed to be zero under normal operation, i.e., outlet valves are supposed closed. In this case:

$$
\mathrm{R}_{5}=\mathrm{R}_{6}=\mathrm{R}_{7}=\mathrm{R}_{8}=\infty
$$

Therefore:

$\mathrm{Q}_{5}=\mathrm{Q}_{6}=\mathrm{Q}_{7}=\mathrm{Q}_{8}=0$.

Flow resistances between the adjacent tanks are:

$$
\mathrm{R}_{4}=1.96 \times 10^{5}\left(\mathrm{~kg} \mathrm{~m}^{-5}\right)
$$

and

$$
\mathrm{R}_{3}=2 \times 10^{5}\left(\mathrm{~kg} \mathrm{~m}^{-5}\right)
$$

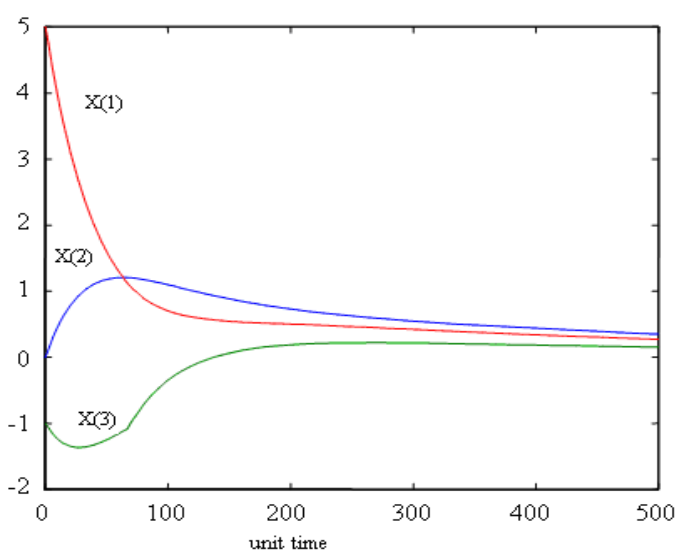

Fig. 4: Trajectories from sliding mode simulation versus time 


$$
\begin{aligned}
{\left[\begin{array}{l}
\Delta \dot{\mathrm{H}}_{1} \\
\Delta \dot{\mathrm{H}}_{2} \\
\Delta \dot{\mathrm{H}}_{3}
\end{array}\right]=} & \left(\begin{array}{ccc}
-0.0044 & 0.0044 & 0 \\
0.0078 & -0.0156 & 0.0078 \\
0 & 0.0044 & -0.0044
\end{array}\right)\left[\begin{array}{l}
\Delta \mathrm{H}_{1} \\
\Delta \mathrm{H}_{2} \\
\Delta \mathrm{H}_{3}
\end{array}\right] \\
& +\left(\begin{array}{cc}
123.3502 & 0 \\
0 & 0 \\
0 & 123.3502
\end{array}\right)\left[\begin{array}{l}
\mathrm{Q}_{1} \\
\mathrm{Q}_{2}
\end{array}\right]
\end{aligned}
$$

The plant dynamic fault is modeled as leakage in tank 2, means that:

$$
\mathrm{R}_{3}=\infty \rightarrow \mathrm{R}_{3}=1 \times 10^{3}\left(\mathrm{~kg} \mathrm{~m}^{-5}\right)
$$

Therefore, under the system initial operating condition, the system model under such a fault becomes:

$$
\begin{aligned}
{\left[\begin{array}{c}
\Delta \dot{\mathrm{H}}_{1} \\
\Delta \dot{\mathrm{H}}_{2} \\
\Delta \dot{\mathrm{H}}_{3}
\end{array}\right]=} & \left(\begin{array}{ccc}
-0.0044 & 0.0044 & 0 \\
0.0078 & -0.0967 & 0.0078 \\
0 & 0.0044 & -0.0044
\end{array}\right)\left[\begin{array}{l}
\Delta_{1} \\
\Delta \mathrm{H}_{2} \\
\Delta \mathrm{H}_{3}
\end{array}\right] \\
& +\left(\begin{array}{cc}
123.3502 & 0 \\
0 & 0 \\
0 & 123.3502
\end{array}\right)\left[\begin{array}{l}
\mathrm{Q}_{1} \\
\mathrm{Q}_{2}
\end{array}\right]
\end{aligned}
$$

The result shown in Fig. 4 (trajectories versus times)shows the points of time where region transitions have occurred and when the system has been sliding (when the state is zero, e.g. around five time units), This result based on full order of the system.

While the simulation shown in Fig. 5 is clearer where system is sliding, we have added a wall between two regions of this system; we can see that the trajectory gets stuck on this surface at couple of points and slides for a while before escaping.

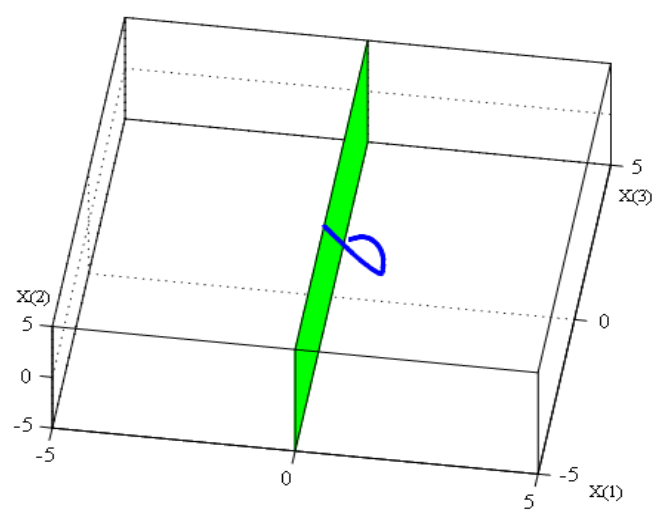

Fig. 5: Three dimension from sliding mode simulation

\section{DISCUSSION}

From the above system model (37), it is clear that the leakage of the tank 2 has caused the changes in the system matrix and such fault is belongs the class of system dynamic faults

Using Matlab and through the Model Order Reduction technique we may obtain the transfer function of (37) as follow:

$\frac{123.4 s+12.89}{s^{2}+0.1011 s+0.0003568}$

Such that we could benefit from the availability of very small models that capture the input-output behavior of complex systems with the same accuracy as the former order.

Then we take (38) as $G$ and we follow the same steps from formula (24) up to (28) finally we obtain the form:

$$
\left\{\begin{array}{l}
{\left[\begin{array}{l}
\dot{x}_{1} \\
\dot{x}_{2}
\end{array}\right]=\left(\begin{array}{cc}
0 & 1 \\
-12.89 & -123.55115
\end{array}\right)\left[\begin{array}{l}
x_{1} \\
x_{2}
\end{array}\right]+\left[\begin{array}{l}
0 \\
0.0003568
\end{array}\right] u} \\
y=[10]\left[\begin{array}{l}
x_{1} \\
x_{2}
\end{array}\right]
\end{array}\right.
$$

With this reduced system the sliding controller design looks easy but this model encounter a chattering phenomenon which push us to add a dead zone to alleviated the chattering, this latter should be well adjusted to get an acceptable result, the Fig. 6, shows the input controller, out put result and the states trajectory of the reduced model.
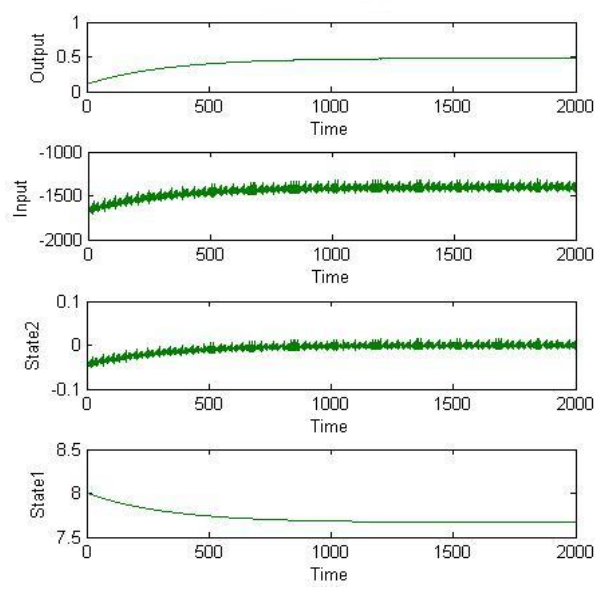

Fig. 6: Simulation result of, input, output, stat variable and its derivative of the reduced system 
This method that we went through will be more interesting to apply to more systems to check its efficiency, at the first stage we will try with symmetric system then for more complex one.

Mean while we are doing networked control system with the same system and the same approach.

\section{CONCLUSION}

Decentralized control theory and the decoupled sliding-mode method, enhanced by piecewise linear sliding mode was presented for controlling 3water level tank divided into two sub systems and the sliding-mode control was performed in manner that gives an easy way to deal with non linearity, then the fault occurrence.

\section{REFERENCES}

Drazenovic, B., 1969. The invariance condition in variable structure systems. Automatica, 5: 287-295. DOI: 10.1016/0005-1098(69)90071-5

El-Ghezaoui, O.M.E., A.S.I. Zinober and S.A. Billings, 1983. Analysis and design of variable structure systems using a geometric approach. Int. J. Control, 38: 657-671. DOI: 10.1080/00207178308933100

Esfandiari, F. and H.K. Khalil, 1991. Stability analysis of a continuous implementation of variable structure control. IEEE Trans. Automat. Control, 36: 616-620. DOI: 10.1109/9.76367

Huzmezan, M. and J. Maciejowski, 1998a. Reconfigurable flight control of a high incidence research model using predictive control. Proceeding of the UKACC International Conference on Control, Sept. 1-4, IEEE Xplore Press, Swansea, UK., pp: 1169-1174. DOI: 10.1049/cp:19980393
Huzmezan, M. and J.M. Maciejowski, 1998b. Reconfiguration and scheduling in flight using quasi-LPV high-fidelity models and MBPC control. Proceeding of the American Control Conference, June 21-26, IEEE Xplore Press, Philadelphia, PA., USA., $\quad$ pp: $3649-3653 . \quad$ DOI: 10.1109/ACC.1998.703294

Johansson, M. and A. Rantzer, 1998. Computation of piecewise quadratic lyapunov functions for hybrid systems. IEEE Trans. Automat. Control 43: 555-559. DOI: $10.1109 / 9.664157$

Khan, M.K. and S.K. Spurgeon, 2006. Robust MIMO water level control in interconnected twin-tanks using second order sliding mode control. Control Eng. Pract., 14: 375-386.

DOI: 10.1016/j.conengprac.2005.02.001

Rauch, H.E., 1995. Autonomous control reconfiguration. IEEE Control Syst. Mag., 15: 37-48. DOI: 10.1109/37.476385

Rauch, H.E., 1994. Intelligent fault diagnosis and control reconfiguration. IEEE Control Syst. Magazine, 14: 6-12. 1994 DOI: 10.1109/37.291462

Slotine, J.J.E. and W. Li, 1991. Applied Nonlinear Control, Prentice-Hall, New Jerst., ISBN 0130408905, pp: 459.

Yang, Z. and M. Blanke, 2000. The Robust control, mixer module method for control reconfiguration. Am. Control Conf. 5: 3407-3411. DOI: 10.1109/ACC.2000.879200 